\title{
Studi Efisiensi Lebar Alas Dinding Penahan Tanah Tipe Kantilever pada Jalan Brigjend Abdul Manan Wijaya Kecamatan Pujon Kabupaten Malang
}

\author{
Vendelinus Agar ${ }^{1 *}$, Suhudi ${ }^{2}$, dan Andy Kristafi Arifianto ${ }^{3}$ \\ Prodi Teknik Sipil, Fakultas Teknik, Universitas Tribhuwana Tunggadewi \\ JL.Telaga Warna Tlogomas Malang,651114,Indonesia \\ *e-mail corresponding author : vendelinus_agar@yahoo.com
}

\begin{abstract}
ABSTRAK
Salah satu metode yang digunakan agar stabilitas tanah tidak terganggu adalah dengan membangun perkuatan dinding penahan tanah. Perencanaan dinding penahan tanah, mempunyai tujuan guna menjaga bangunan tersebut aman terhadap guling, geser dan daya dukung tanah sepanjang garis dinding penahahan tanah tersebut. Penelitian ini dilakukan dalam beberapa tahapan, mulai dari tahap persiapan, pengumpulan data primer (survei, pengukuran, dokumentasi, analisis tanah di laboratorium) dan data sekunder (gambar kerja, peta lokasi, daftar harga satuan) yang di perlukan dalam analisis. Data primer dan data sekunder diperlukan guna mendukung penelitian ini seperti mengumpulkan dan mengolah data, menentukan jenis tanah, menentukan jenis dinding penahan tanah, menentukan dimensi dinding penahan tanah, menghitung stabilitas tanah, menghitung rencana anggaran biaya terhadap dimensi dinding penahan tanah yang stabil, gambar detail dinding penahan tanah yang direncanakan. Dari hasil analisa dan pembahasan mengenai lebar alas dinding penahan tanah tipe kantilever di Jalan Brigjend Abdul Manan Wijaya, Kecamatan Pujon, Kabupaten Malang dapat disimpulkan bahwa: tinggi $(\mathrm{h})=7,00 \mathrm{~m}$, lebar pandasi $(\mathrm{b})=2,5 \mathrm{~m}$, lebar atas dinding penahan $=0,4 \mathrm{~m}$, kedalaman pondasi $=1 \mathrm{~m}$, tinggi total $=8,00 \mathrm{~m}$ dan total dana yang dibutuhkan untuk perencanaan dinding penahan tanah tipe kantilever $=$ Rp. 226.000.000,00.
\end{abstract}

Kata Kunci : Studi efisiensi, Dinding penahan, Tipe kantilever

\section{ABSTRACT}

The method used to control the stability of the soil so that it does not experience landslides is by building a retaining wall. The construction of a retaining wall aims to maintain infrastructure and infrastructure plans to remain safe against rolling, shearing and carrying capacity of the land along the wall lines of the land for a long time (structurally strong) is a demand that must be carried out to protect the infrastructure from its failure. This research was carried out in several stages, starting from the preparation stage, collecting primary data, namely survey methods, measurements, documentation, laboratory experiments (soil types) and secondary data namely work drawings, location maps, list of unit prices needed in the analysis. Data analysis and steps in this study are: determining location, collecting data, through primary data and secondary data in supporting literature such as collecting and processing data, determining the type of soil, determining the type of retaining wall, determining the dimensions of the retaining wall, calculate the stability of rolling, shear and bearing capacity of the soil, calculate the budget plan against the dimensions of a stable retaining wall, draw details of the planned retaining wall planned. From the results of analysis of calculations and discussion of the Width of the Cantilever Type Ground Retaining Wall on street Brigjend Abdul Manan Wijaya, Pujon Subdistrict, Malang Regency can be concluded as follows: height (b) $=7.00 \mathrm{~m}$, width of width (b) $=2,5 \mathrm{~m}$, the width of the retaining wall $=0.4 \mathrm{~m}$, foundation depth $=1 \mathrm{~m}$, total height $=8.00 \mathrm{~m}$ and the total cost design for the construction of cantilever type retaining wall $=\mathrm{R}$. 226,000,000.00.

Keywords: efficiency studies, retaining wall, cantilever type

Cara Mengutip : Agar, V., Suhudi, Arifianto, A. K (2020). Studi Efisiensi Lebar Alas Dinding Penahan Tanah Tipe Kantilever pada Jalan Brigjend Abdul Manan Wijaya Kecamatan Pujon Kabupaten Malang. Reka Buana : Jurnal Ilmiab Teknik Sipil dan Teknik Kimia, 5(1), 90-97. http://dx.doi.org/10.33366/rekabuana.v5i1.1739 


\section{PENDAHULUAN}

Tanah merupakan aspek penting dalam perencanaan konstruksi. Tanah adalah media tempat berdirinya suatu bangunan (Foth, 1994). Oleh sebab itu, daya dukung tanah sangat diperhatikan agar tanah mampu menahan bangunan tersebut. Salah satu cara yang digunakan untuk mengontrol kestabilan tanah agar tak mengalami gangguan adalah dengan membangun dinding penahan tanah (Djatmiko, 1993).

Pembuatan dinding penahan tanah harus berdasarkan faktor keselamatan kerja dan analisa kestabilan karena kesalahan yang terjadi dalam pembangunan dinding penahan tanah dapat berakibat pada kerugian harta dan hilangnya korban jiwa (Tarzaghi, 1993).

Salah satu contoh adalah runtuhnya bangunan perlindungan lereng tanah pada Jalan Brigjend Abdul Manan Wijaya Kecamatan Pujon Kabupaten Malang, yang mengakibatkan terganggunya pengguna jalan dan sarana transportasi yang melintasi di lokasi kejadian. Oleh karena itu pada penelitian ini bermaksud untuk meneliti tentang studi efisiensi lebar alas dinding penahan tanah kantilever pada Jalan Brigjend Abdul Manan Wijaya, Kecamatan Pujon Kabupaten Malang.

\section{Jenis - Jenis Dinding Penahan Tanah}

Beberapa jenis dinding penahan tanah adalah sebagai berikut (Hardiyatmo, 2010):

- Dinding Gravitasi (Gravity wall) Dinding yang terbuat dari beton tidak bertulang atau pasangan batu kali. Untuk mencapai stabilitasnya hanya mengandalkan berat sendiri.

- Dinding Penahan Kantilever

Dinding penahan kantiliver terbuat dari beton bertulang dengan susunan dinding vertikal dan tapak lantai. Peranan masing-masing susunan itu sebagai balok atau pelat kantiliver. Berat dinding penahan dan berat tanah di atas hell (tumit tapak) merupakan faktor penentu stabilitas konstruksinya. Bagian-bagian struktur yang berperan sebagai kantiliver, yaitu bagian dinding vertikal (steem), ujung kaki tapak (toe) dan tumit tapak. Ketinggian dinding biasanya $<6 \mathrm{~m}$.

- Dinding Kontrafrot

Jika tekanan tanah aktif pada dinding vertikal sangat besar, maka bagian tumit dan dinding vertikal perlu disatukan (kontrafort). Fungsi dari kontrafort sebagai pengikat tarik dinding vertikal dan diletakkan pada bagian timbunan dengan jarak tertentu. Lebih ekonomis dinding kontrafort digunakan jika ketinggian dindingnya $>7$ meter.

\section{- Dinding Buttress}

Jenis dinding ini hampir sama dengan dinding kontrafort, akan tetapi perbedaannya pada bagian kontrafort diletakkan di depan dinding. Hal ini disebabkan karena struktur kontrafort berfungsi memikul tegangan tekan. Pada dinding ini, bagian tumit (hell) lebih pendek daripada bagian kaki. Berat dinding penahan dan berat tanah di atas bell merupakan faktor penentu stabilitas konstruksinya. Jenis dinding penahan ini lebih ekonomis jika ketinggian dindingnya lebih dari 7 meter.

\section{Tanah}

Tanah adalah alas dari pada suatu konstruksi yang mempunyai fungsi sebagai pendukung pondasi pada suatu bangunan (Hardiyatmo, 2002 dan Hardiyatmo, 2003). 
Tanah mempunyai 3 bagian adalah bagian padat atau butiran, pori-pori udara dan air pori. Bagian-bagian tanah dapat ditampilkan dalam bentuk diagram fase pada Gambar 1 berikut ini.

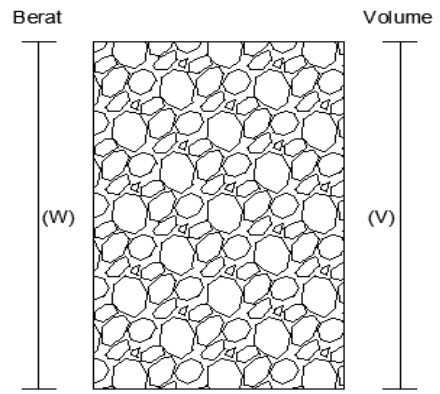

(a)

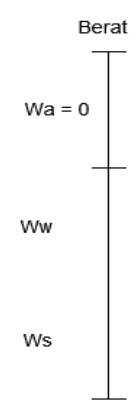

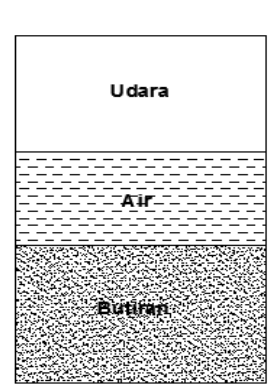

(b)

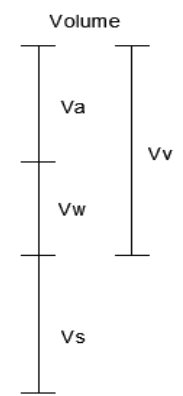

$\perp$

Gambar 1. Diagram Fase Tanah

\section{Drainase Pada Dinding Penahan Tanah}

Perencanaan dinding penahan tanah diperlukan suatu sistem drainase, karena tanah isian yang terendam oleh air akan menyebabkan (Wesley, 1997):

- Tekanan hidrostatik pada dinding sepanjang dinding penahan tanah,

- Adanya tekanan air pori yang besar dapat menaikkan tekanan tanah yang bekerja pada dinding.

Untuk meminimalisasi atau mereduksi pengaruh - pengaruh tersebut di atas, dibutuhkan sistem drainase yang baik sehingga perancangan dinding penahan tanah lebih aman (Craig, 1987).

\section{Jenis Drainase Pada Dinding Penahan Tanah}

- Drainase Dasar

Drainase dasar merupakan sistem drainase yang sangat sederhana yaitu air yang berada di belakang dinding dikumpulkan dan selanjutnya dialirkan ke depan dinding melalui saluran pipa/lobang yang menembus dinding penahan tanah.

- Drainase Punggung
Drainase punggung merupakan sistem drainase yang lebih baik dibandingkan dengan drainase dasar, karena pada sepanjang punggung dinding penahan tanah lateral terdapat material filter, dimana prinsip kerjanya sama dengan drainase dasar.

- Drainase Inklinasi dan Horisontal

Kedua sistem drainase ini dimaksudkan untuk menghilangkan tekanan air pori yang berlebihan. Pada kedua jenis sistem drainase ini gaya aliran (see page force) berarah ke bawah menuju ke sistem drainase

(Herlien, 2011).

Pada prinsipnya kondisi tanah dalam kedudukannya ada 3 kemungkinan, Yaitu (Das dkk, 1983) :

- Dalam Keadaan Diam (Ko )

- Dalam Keadaan Aktif ( Ka)

- Dalam Keadaan Pasif ( Kp )

\section{Bahaya Guling}

Persamaan stabilitas struktur terhadap guling dihitung dengan berikut (Hakim, 2011):

Sf guling $=\frac{\sum M}{\sum M H} \geq 1,5$ 
Keterangan:

$\sum \mathrm{M}=$ jumlah dari momen - momen yang menyebabkan struktur terguling dengan titik pusat putaran di titik 0. $\sum \mathrm{M}$ disebabkan oleh tekanan tanah aktif yang bekerja pada elevasi $\mathrm{H} / 3$

$\sum \mathrm{MH}=$ jumlah dari momen - momen yang mencegah struktur terguling dengan titik pusat putaran di titik 0 . $\sum \mathrm{MH}$ merupakan momen - momen yang disebabkan oleh gaya vertikal dari struktur dan berat tanah diatas struktur

Nilai angka keamanan minimum terhadap guling dalam perencanaan digunakan adalah 1,5 .

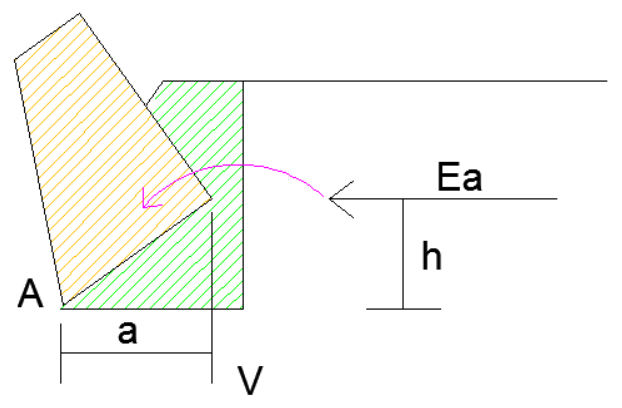

Gambar 2. Keruntuhan Akibat Bahaya Guling

\section{Bahaya Geser}

Dinding penahan tanah dalam keadaan stabil, jika gaya - gaya yang bekerja dalam keadaan seimbang.

$$
\left(\sum \mathrm{F}\right)=0 \text { dan } \sum \mathrm{M}=0
$$$$
\text { Gaya aktif tanah (Eg) selain }
$$
menimbulkan terjadinya momen juga menimbulkan gaya dorong sehingga dinding akan bergeser.

Perlawanan terhadap gaya dorong ini terjadi pada bidang kontak antara tanah dasar pondasi.

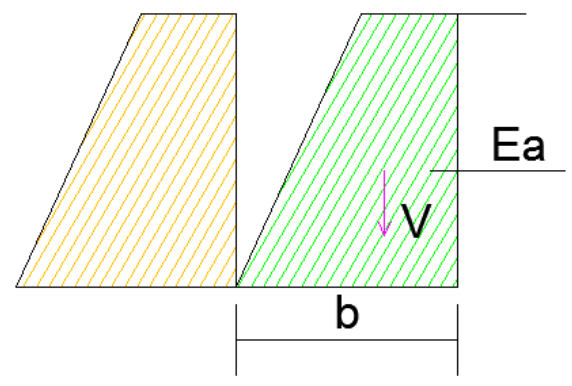

Gambar 3. Keruntuhan Terhadap Bahaya

\section{METODE PENELITIAN}

\section{Lokasi Penelitian}

Lokasi penelitian terletak pada Jalan Brigjend Abdul Manan Wijaya, Dusun Lebak Sari, Desa Ngroto, Kecamatan Pujon Kabupaten Malang Propinsi Jawa Timur.

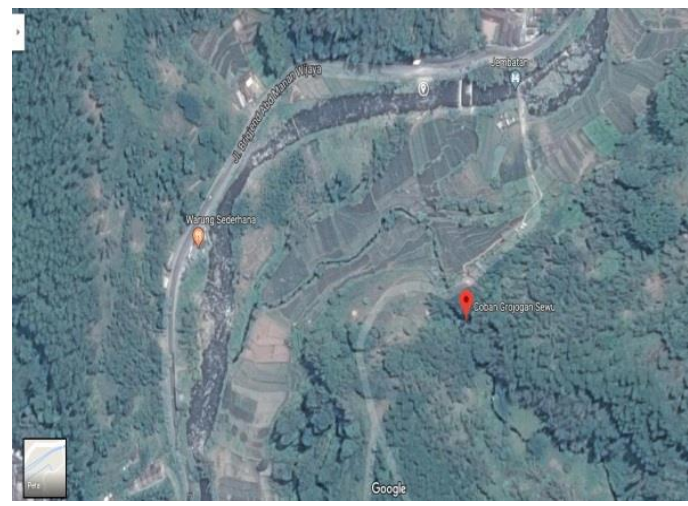

Gambar 4. Lokasi Perencanaan (Sumber: Google Earth 2017)

\section{Metode Pengumpulan Data}

Data yang digunakan dalam penelitian ini yaitu data primer yang didapati dengan melakukan sendiri dilapangan dan data sekunder yang didapat dari instansi (Dinas Perumahan dan Pemukiman Kabupaten Malang).

- Data Primer

* Survei lapangan

* Pengukuran

Dokumentasi

Analisis tanah di laboratorium 
- Data Sekunder

* Gambar kerja

* Peta lokasi

* Daftar harga satuan.

\section{Tahapan Pengolahan Data}

Tahapan analisa merupakan tahap pengolahan data dari hasil pengumpulan data yang dikelompokkan sesuai dengan perumusan masalah. Analisa data serta langkah-langkah dalam penelitian ini yaitu:

- Menentukan lokasi

- Pengumpulan data, melalui data primer dan data sekunder pada literature pustaka yang mendukung.

- Menentukan jenis tanah.

- Menentukan jenis dan dimensi dinding penahan tanah

- Menghitung stabilitas terhadap guling, geser dan daya dukung tanah.
- Menghitung Rencana Anggaran Biaya (RAB) terhadap dimensi dinding penahan tanah yang stabil.

- Gambar detail dinding penahan tanah yang direncanakan.

\section{HASIL DAN PEMBAHASAN}

\section{Data Perencanaan}

Dinding penahan tanah yang direncanakan di Jalan Brigjend Abdul Manan Wijaya, Kecamatan Pujon sepanjang $17 \mathrm{~m}$. Berdasarkan hasil pengujian sampel tanah di Laboratorium Tanah Universitas Tribhuwana Tunggadewi Malang dan dianggap data sudah memenuhi syarat didapatkan data-data sebagai berikut :

Tinggi air $\left(\mathrm{H}_{\text {air }}\right)$

- Normal $=0,60 \mathrm{~m}$

- Banjir = 1,60 m

Tabel 1. Kohesi Sudut Geser Ø (Dalam Derajat)

\begin{tabular}{|c|c|c|c|c|}
\hline \multirow[t]{2}{*}{ Kondisi } & \multicolumn{3}{|c|}{ Tanah } & \multirow[b]{2}{*}{ Krikil } \\
\hline & Lapuk & Lempung & Pasir & \\
\hline Kering & $20-40$ & $20-37$ & $2227-40$ & $30-45$ \\
\hline Lembab & $30-45$ & $40-45$ & $330-45$ & $27-40$ \\
\hline Dengan KandunganAir Yang Tinggi & $14-27$ & $14-20$ & $20-30$ & $25-30$ \\
\hline
\end{tabular}

- Tanah pengisi = Tanah Berpasir

- Kohesi Tanah (c) = 2

- Sudut Geser $(\varphi) \quad=40^{\circ}$

\section{Tabel 2. Kohesi C dan Sudut Geser-} Dalam Ø

\begin{tabular}{lcc}
\hline Jenis Tanah & $\mathbf{C}(\mathbf{T} /)$ & $\mathbf{\phi}\left(^{\circ}\right)$ \\
\hline Lumpur pasiran & 2,0 & 3 \\
Lempung padat & 7,5 & 8 \\
Lempung & 5,0 & 6 \\
Lempung lunak & 2,0 & 4 \\
Lempung sangat lunak & 1,0 & 2 \\
Lumpur & 0,5 & 0 \\
\hline
\end{tabular}

- Berat Volume Pasangan ( $\gamma$ beton bertulang) $=24 \mathrm{kN} / \mathrm{m} 3$

- Berat Volume Air $(\gamma \mathrm{w})$

$$
=9,81 \mathrm{kN} / \mathrm{m} 3
$$

- Angka Pori (e) =1,01

- Kadar air $(\mathrm{w})=55,82 \%(55,82 / 100)=$ 0,5582\%

- Berat Isi Tanah $(\gamma \mathrm{b})=1,48 \mathrm{gr} / \mathrm{cm}^{3}=$ $\frac{1,48 \times 1000 \times 10}{1000}=14,80 \mathrm{kN} / \mathrm{m}^{3}$

- Berat Volume Tanah Kering $(\gamma \mathrm{d})=$ $\frac{\gamma \mathrm{b}}{1+w}=\frac{14,80}{1+0,01}=9,50 \mathrm{kN} / \mathrm{m}^{3}$

- Berat Volume Tanah Jenuh ( $\gamma$ sat) $=$ $\frac{(\mathrm{Gs}+\mathrm{e}) \gamma \mathrm{w}}{1+e}=\frac{(1,81+1,01) \cdot 9,81}{1+1,01}=13,76 \mathrm{kN} / \mathrm{m}^{3}$ 
Tabel 3. Data Tanah

\begin{tabular}{|c|c|c|c|c|}
\hline No. & Jenis Data & Notasi & Angka & Satuan \\
\hline 1 & $\begin{array}{l}\text { Berat Jenis } \\
\text { Tanah }\end{array}$ & Gs & 1,81 & $\mathrm{kN} / \mathrm{m}^{3}$ \\
\hline 2 & $\begin{array}{l}\text { Berat } \\
\text { Volume } \\
\text { Tanah Basah }\end{array}$ & $\gamma_{\mathrm{b}}$ & 14,80 & $\mathrm{kN} / \mathrm{m}^{3}$ \\
\hline 3 & $\begin{array}{l}\text { Berat } \\
\text { Volume } \\
\text { Tanah } \\
\text { Kering }\end{array}$ & $\gamma_{\mathrm{d}}$ & 9,50 & $\mathrm{kN} / \mathrm{m}^{3}$ \\
\hline 4 & $\begin{array}{l}\text { Berat } \\
\text { Volume } \\
\text { Tanah Jenuh }\end{array}$ & $\gamma_{\text {sat }}$ & 13,76 & $\mathrm{kN} / \mathrm{m}^{3}$ \\
\hline 6 & $\begin{array}{l}\text { Berat Jenis } \\
\text { Air }\end{array}$ & $\gamma_{\mathrm{w}}$ & 9,81 & $\mathrm{kN} / \mathrm{m}^{3}$ \\
\hline 7 & $\begin{array}{l}\text { Berat Jenis } \\
\text { beton }\end{array}$ & $\Gamma$ & 24,00 & $\mathrm{kN} / \mathrm{m}^{3}$ \\
\hline 8 & Angka Pori & $\mathrm{E}$ & 1,01 & \\
\hline 9 & $\begin{array}{l}\text { Kohesi } \\
\text { Tanah }\end{array}$ & C & 2 & $\mathrm{t} / \mathrm{m}^{3}$ \\
\hline 10 & Sudut Geser & $\Phi$ & 40 & $\circ$ \\
\hline
\end{tabular}

Sumber : Laboratorium Tanah Universitas Tribhuwana Tunggadewi Malang

\section{Perencanaan Dinding Penahan Tanah}

Dinding penahan tanah yang direncanakan adalah jenis dinding penahan Kantilever. Data Perencanaan :

Tinggi Total $(\mathrm{H}+\mathrm{D})=8,00 \mathrm{~m}$

Tinggi Dinding Penahan $(\mathrm{H})=7.0 \mathrm{~m}$

Lebar Bawah (c) $=1.00 \mathrm{~m}$

Lebar Atas (a) $\quad=0.40 \mathrm{~m}$

Kedalaman pondasi $(\mathrm{d})=1.00 \mathrm{~m}$

Lebar pondasi $(B)=2.50 \mathrm{~m}$

Tabel 4. Hasil Perhitungan Momen Akibat Gaya Vertikal

\begin{tabular}{|c|c|c|c|}
\hline No & $\begin{array}{r}\text { Berat } \\
\text { Sendiri } P \\
(\mathrm{kN} / \mathrm{m})\end{array}$ & $\begin{array}{l}\text { Jarak ke } \\
\text { titik } 0 \text { (m) }\end{array}$ & $\begin{array}{l}\text { Momen } \\
\text { (kN.m) }\end{array}$ \\
\hline 1 & 168,00 & 1,30 & 218,40 \\
\hline 2 & 50,40 & 0,90 & 45,36 \\
\hline 3 & 60,00 & 1,25 & 75,00 \\
\hline 4 & 103,60 & 2,00 & 207,20 \\
\hline $\bar{\Sigma}$ & 382,00 & & 545,96 \\
\hline
\end{tabular}

\section{Kapasitas Dukung Tanah}

Kapasitas dukung ultimate : $\mathrm{qu}=\left(\frac{1}{3} \cdot \mathrm{c} \cdot \mathrm{Nc}\right)+(\gamma \cdot \mathrm{d} \cdot \mathrm{Nq})+(0,4 \cdot \gamma$

B. $N \gamma$ )

Keterangan : $\mathrm{Nc}, \mathrm{Nq}, \mathrm{Ny}$ adalah faktor kapasitas dukung tanah(fungsi $\phi 40^{\circ}$ ), diambil dari grafik Terzaghi.

Didapatkan nilai :

$\mathrm{Nc}=95,7$

$\mathrm{Nq}=81,3$

$\mathrm{N} \gamma=100,4$

$P_{o}=d f \cdot \gamma$ sat $=2 \cdot 13,76=27,53 \mathrm{kN} / \mathrm{m}^{2}$ $\mathrm{qu}=\left(\frac{1}{3} \cdot 1,8 \cdot 95,7\right)+(22 \cdot 2 \cdot 81,3)+$ $(0,4 \cdot 22 \cdot 2,5 \cdot 100,4)=6368,85 \mathrm{kN} / \mathrm{m}^{2}$

Kapasitas dukung ultimit neto:

$$
\begin{aligned}
\text { Qun } & =\text { qu }- \text { Po } \\
& =6368,85-27,53 \\
& =6341,32 \mathrm{kN} / \mathrm{m} 2
\end{aligned}
$$

Tekanan pondasi neto:

$$
\begin{aligned}
\text { Qn } & =\text { qun }- \text { Po } \\
& =6341,32-27,53 \\
& =6313,80 \mathrm{kN} / \mathrm{m} 2
\end{aligned}
$$

Faktor aman $(\mathrm{f})=3$

Kapasitas dukung ijin:

$$
\begin{aligned}
\mathrm{qa} & =\frac{\mathrm{qu}}{\mathrm{f}} \\
& =\frac{6368,85}{3} \\
& =2122,95 \mathrm{kN} / \mathrm{m} 2
\end{aligned}
$$

Faktor Keamanan Terhadap Kuat Dukung Tanah, Geser dan Guling

- Stabilitas terhadap daya dukung tanah

$\sum \mathrm{M}=479,16 \mathrm{kNm}$

$\mathrm{V}=\sum \mathrm{P}=348,60 \mathrm{kN} / \mathrm{me}$

$=1 / 2 \cdot \mathrm{B}-\frac{\sum M}{\sum P}$ 


$$
\begin{aligned}
&=1 / 2 \quad 2,5-\frac{479,16}{348,60}=0,12 \mathrm{e}_{\mathrm{ijin}} \\
&=\frac{1}{6} \cdot \mathrm{B}=\frac{1}{6} \cdot 2,5=0,42 \\
& \sigma \max =\frac{2 \cdot V}{3 \cdot\left(\frac{B}{2}\right)-e} \\
&=\frac{2 \cdot 348,60}{3 \cdot\left(\frac{2,5}{2}\right)-(-0,12)}=179,94 \mathrm{~km}^{2} \\
& \sigma \max =179,94 \mathrm{kN} / \mathrm{m}^{2}<\mathrm{qa}=2122,95 \\
& \mathrm{kN} / \mathrm{m}^{2} \ldots \ldots . .(\mathrm{Ok})
\end{aligned}
$$

\section{- Stabilitas terhadap geser}

$$
\begin{aligned}
\mathrm{F} & =\operatorname{tg}, \operatorname{tg} 40=0,839 \\
\mathrm{SF} & =\frac{(v \cdot f)+\left(\frac{2}{3} \cdot c \cdot B\right)+(P p)}{P a} \\
& =\frac{(382 \cdot 0,839)+\left(\frac{2}{3} \cdot 2 \cdot 2,5\right)+(154,52)}{169,91} \\
& =1,953>1,5 \ldots . .(O k)
\end{aligned}
$$

\section{- Stabilitas terhadap guling}

$$
\begin{aligned}
\sum \mathrm{Ma} & =372,68 \mathrm{kNm} \\
\sum \mathrm{Mp} & =81,00 \mathrm{kNm} \\
\sum \mathrm{M} & =479,16 \mathrm{kNm} \\
\mathrm{SF} & =\frac{\sum M+\sum M p}{\sum M a} \\
& =\frac{479,16+81,00}{372,68} \\
& =\frac{678,41}{372,68}=1,503>1,5 \ldots \ldots \ldots . .(\mathrm{Ok})
\end{aligned}
$$

\section{KESIMPULAN}

Hasil analisis perhitungan dan pembahasan dapat disimpulkan beberapa hal mengenai lebar alas dinding penahan tanah tipe kantilever sebagai berikut:

1. Dimensi dinding penahan tanah yang direncanakan:

Tinggi $(\mathrm{H})=7,00 \mathrm{~m}$

Lebar pandasi $(B)=2,5 \mathrm{~m}$

Lebar atas dinding penahan $=0,4 \mathrm{~m}$

Kedalaman pondasi $=1 \mathrm{~m}$

Tinggi total $=8,00 \mathrm{~m}$
2. Hasil analisa stabilitas dinding penahan, ternyata stabil terhadap:

Untuk kondisi normal tanpa gempa:
a. Bahaya Geser, $\mathrm{SF}=1,953>1,5$
b. Bahaya Guling, $\mathrm{SF}=1,503>1,5$
Untuk kondisi banjir tanpa gempa:
a. Bahaya Geser, $\mathrm{SF}=2,156>1,5$
b. Bahaya Guling, $\mathrm{SF}=1,763>1,5$

3. Total biaya yang diperlukan untuk pembangunan dinding penahan tanah kantilever dengan panjang $17 \mathrm{~m}$ dan lebar 2,5 m sebesar Rp. 226.000.000,00. Biaya pekerjaan setiap $\mathrm{m}^{3}=\mathrm{Rp}$. $1,359,316.73$

\section{DAFTAR PUSTAKA}

[1] Foth Henry dan Soenarto Adisoemarto. 1994. Dasar - Dasar Ilmu Tanah, Penerbit Erlangga : Jakarta

[2] Djatmiko Soedarmono, Edy Purnomo. 1993. Mekanika Tanah 2. Kanisius : Jogjakarta.

[3] Terzaghi, K, \& Peck. R, B. 1993. Mekanika Tanah dalam Praktik Rekayasa. Erlangga : Jakarta.

[4] Hardiyatmo, H. C. 2010. Mekanika Tanah II. Edisi Ketiga. Universitas Gajah Mada : Jogjakarta.

[5] Hardiyatmo, H. C. 2002.Mekanika Tanah I. Edisi Ketiga. Universitas Gajah Mada : Jogjakarta

[6] Hardiyatmo, H. C. 2003. Mekanika Tanah II. Edisi Ketiga. Universitas Gajah Mada : Jogjakarta.

[7] L. D. Wesley. 1997. Mekanika Tanah. Badan Penerbit Pekerjaan Umum : Jakarta.

[8] R. F. Craig. 1987. Mekanika Tanah. Erlangga : Jakarta. 
[9] Herlien Indrawahjuni. 2011. Mekanika Tanah II. Bargie Media : Malang.

[10] Das, B.M., Noor, E. dan Mochtar, I.B., 1983, Mekanika Tanah Jilid 2. Penerbit Erlangga : Jakarta.

[11] Hakim, Abd, dan Mulya, R.P, 2011, Studi Stabilitas Dinding Penahan Tanah Kantilever pada Ruas Jalan Silaing Padang Bukit Tinggi KM 64+500, Jurnal Rekayasa Sipil Vol 7 Februari 2011, Universitas Andalas: Padang. 